\title{
PROFESSORES INICIANTES EM CURSOS DE COMUNICAÇÃO SOCIAL DO RIO DE JANEIRO
}

\author{
Julio Cesar Santos da Silva ${ }^{1}$, Laélia Portela Moreira ${ }^{2}$
}

${ }^{1}$ Mestre em Educação pela Universidade Estácio de Sá - UNESA, Docente da Universidade Castelo Branco - UCB, RJ.
${ }^{2}$ Doutora em Educação pela Universidade Federal do Rio de Janeiro - UFRJ. Docente e Pesquisadora do Programa de
Pós-Graduação em Educação da Universidade Estácio de Sá - UNESA. E-mail: moreira.laelia@gmail.com

\section{RESUMO}

A ausência de políticas voltadas para a formação de professores que atuam em Instituições de Ensino Superior (IES), no Brasil, representa relevante ponto de atenção, e diversos são os autores que têm, mais recentemente, chamado atenção para a importância da formação dos docentes que atuam nesse nível de ensino, tanto em IES públicas, quanto privadas. $O$ artigo apresenta os resultados de uma pesquisa que buscou analisar os principais desafios no início da atividade docente enfrentados por professores de cursos de Comunicação Social, contratados em razão de sua expertise profissional, sem que tivessem, contudo, formação pedagógica. Trata-se de pesquisa qualitativa, cuja análise foi realizada a partir de dados obtidos por meio de entrevistas semiestruturadas com docentes de duas IES privadas do Rio de Janeiro. Os resultados indicaram diversos tipos de dificuldades enfrentadas na prática docente pelos entrevistados, os quais, na ausência de políticas e iniciativas institucionais voltadas para a formação pedagógica, contaram apenas com a ajuda informal de seus pares, desenvolveram estratégias próprias para o exercício da função, e valeram-se também, em muitos casos, de sua expertise profissional, engendrando diferentes estratégias para o enfrentamento das dificuldades apresentadas no cotidiano da sala de aula.

Palavras - chave: Início na docência. Formação pedagógica. Docência no ensino superior. Instituições de ensino superior privadas. Curso de Comunicação Social.

\section{INITIATING TEACHERS IN MEDIA COURSES IN RIO DE JANEIRO}

\begin{abstract}
The absence of policies aimed at the training of teachers working in Higher Education Institutions (HEIs) in Brazil represents an important point of attention, and several authors have more recently called attention to the importance of teacher training who work at this level of education, both public and private HEls. The article presents the results of a research that sought to analyze the main challenges at the beginning of the teaching activity faced by teachers of Social Communication courses hired because of their professional expertise, without having, however, pedagogical training. This is a qualitative research, whose analysis was based on data obtained through semi-structured interviews with professors from two private HEls in Rio de Janeiro. The results indicated several types of difficulties faced by teachers in the teaching practice, which, in the absence of institutional policies and initiatives geared to pedagogical training, relied only on the informal help of their peers, developed their own strategies for the exercise of their function, and in many cases, their professional expertise, engendering different strategies for coping with the difficulties presented in the daily routine of the classroom.
\end{abstract}

Keywords: Beginning in teaching. Pedagogical training. Teaching in higher education. Private higher education Institutions. Media Course.

\section{INTRODUÇÃO}

O início da docência representa um período pleno de desafios e de destacada importância na constituição da carreira e identidade do professor, em qualquer dos níveis de atuação, tanto em instituições públicas quanto privadas. Nesse contexto, os trabalhos que tratam do período de "indução profissional" (NÓVOA, 2017) indicam, de modo geral, a importância de políticas de acolhimento e acompanhamento dos 
profissionais iniciantes, evidenciando também a necessidade de ampliação de trabalhos empíricos sobre o tema e de políticas públicas direcionadas ao atendimento das necessidades formativas dos professores, nos primeiros anos de sua inserção na docência.

Quanto à docência em Instituições de Ensino Superior (IES), é possível afirmar que, no Brasil, a despeito do crescimento de publicações recentes sobre o assunto, este é ainda um campo relativamente recente, e que pode ser considerado, em muitos aspectos, desconhecido. Trata-se, na verdade, de um objeto pouco explorado, e diversos são os autores (ISAIA, 2006; VEIGA, 2006; MASETTO 2012; GATTI, 2016; THERRIEN; DIAS; LEITINHO, 2016; CRUZ, 2017) que apontam, como problema comum aos setores público e privado, a ausência de políticas públicas e mesmo de iniciativas institucionais voltadas para a formação pedagógica dos docentes que atuam nesse nível educacional.

No que diz respeito ao setor público, é comum, na literatura pertinente, a constatação de que a formação de professores em cursos de pósgraduação stricto sensu negligencia a formação para a docência, uma vez que os cursos de mestrado e doutorado enfatizam a formação do pesquisador, em detrimento da formação do professor. No tocante ao setor privado, o problema é ainda mais grave, visto que tem se tornado cada vez mais comum a contratação de professores portadores apenas do título de bacharel, especialmente em cursos em que a expertise profissional e o conhecimento do mercado relacionado à profissão em tela tornamse ativos relevantes.

A questão é que a expertise profissional não basta. Assim, algumas indagações se impõem: Como se tornam professores? Que desafios enfrentam no cotidiano da sala de aula? Que tipo de saberes, além daqueles próprios de sua formação disciplinar, mobilizam para dar conta do cotidiano da sala de aula?

O que, de um modo geral, se constata é que somente os conhecimentos prático e técnico não são suficientes para a atuação na docência em nível superior. Além da necessidade de compreender o que constitui a atividade de ensinar, e sua relação com a formação do professor em um contexto mais amplo, importa, também, investigar como se dá a construção dos saberes pedagógicos no exercício da docência, já que inexistem políticas públicas que tenham como objetivo esse tipo de formação.
O percurso do professor universitário pode ser definido como um caminho longo. Uma jornada solitária e autodidata, durante a qual as IES, em geral, não oferecem qualquer tipo de suporte ou mesmo um ambiente que favoreça a construção coletiva, e possibilite dirimir dúvidas e compartilhar experiências e conhecimentos.

Segundo Veiga (2006, p. 88), a Lei de Diretrizes e Bases da Educação Nacional, (BRASIL, 1996) é vaga nesse aspecto, remetendo a formação do professor universitário para os programas de mestrado e doutorado. Mais recentemente, reforçando essa argumentação, Cruz (2017) mostra que o lócus de formação do professor de ensino superior são Programas de pós-graduação stricto sensu onde, em detrimento da formação do professor, formam-se, de fato, os especialistas e pesquisadores. Como se formam, então, os docentes que atuam nas milhares de IES brasileiras?

Para Therrien, Dias e Leitinho (2016, p. 22):

A docência universitária também requer formação profissional específica para seu exercício, a fim de ultrapassar os limites entre a formação/profissionalizaçã o e o pragmatismo impostos pelo desconhecimento, por parte dos professores e das Instituições de Educação Superior (IES), da necessária formação pedagógica, pela falta de política pública para formação docente nesse nível e pela falta de uma política institucional consistente e permanente em cada IES.

Tamanha fragilidade no que se refere à formação desse tipo de docente levanta preocupações, especialmente diante do fato de que, nas últimas décadas, foi crescente o número de estudantes que ingressaram no ensino superior, provocando a necessidade, por parte de algumas IES, de aumentar o quadro docente; as públicas por meio de concurso, no qual não há garantias de formação para a docência universitária; as privadas, encontrando a solução na contratação de profissionais oriundos do mundo do trabalho, porém, sem preparo formal 
para a docência. Nesse último caso, especialmente em cursos de perfil profissional mais acentuado, muitas vezes os profissionais são recrutados por serem bem-sucedidos em suas profissões, mesmo que não detenham qualquer experiência docente anterior.

Como se pode observar, não são poucos os desafios da docência no ensino superior e muitos são os autores que tratam das questões discutidas anteriormente. Entretanto, são poucos os estudos que levam em conta a prática desses professores, as dificuldades que enfrentam, e as estratégias que forjam no cotidiano de suas salas de aula para realizarem um trabalho satisfatório, especialmente quando se trata do setor privado, que responde atualmente por $75 \%$ das matrículas na Educação Superior (BRASIL, 2018).

A pesquisa apresentada neste trabalho foi motivada pela problemática mencionada, e teve como objetivo investigar os desafios enfrentados por docentes da área de Comunicação Social, atuantes em duas IES privadas do Rio de Janeiro. Compreendeu, além da revisão de literatura sobre o assunto, a busca por informações fornecidas pelos próprios professores a respeito de sua experiência. Investigar como são enfrentados os desafios da docência do professor de Comunicação Social, na condição de docente no ensino superior privado no Rio de Janeiro, e o modo como esse profissional transita entre o mercado e a sala de aula, se impôs como objetivo principal da pesquisa, cujos resultados serão apresentados nas seções seguintes.

$O$ trabalho foi dividido em duas partes principais: A primeira traz uma discussão sobre docência e ensino superior; a segunda apresenta a pesquisa de campo, por meio da análise das respostas obtidas através de 10 entrevistas com professores que lecionam no ensino superior no curso de Comunicação Social em duas Instituições de Ensino Superior privadas do Rio de Janeiro.

\section{Desenvolvimento profissional e docência no ensino superior}

A palavra docente descende do latim docens, docentis, sendo o particípio presente do verbo latino docere que significa "ensinar". Docente, portanto, é aquele que ensina, instrui e informa. Sendo a docência o trabalho dos professores, essa profissão pode ser desenvolvida durante uma carreira, sendo constantemente moldada de acordo com interferências do cotidiano institucional, profissional, pessoal e social (ROLDÃO, 2007). A docência não é um ofício realizado apenas na sala de aula. Conforme Pimenta e Anastasiou (2002, p. 178), "é uma forma de intervir na realidade social.".

A profissão docente pode ser duplamente distinguida pela versatilidade e também pela ausência de modelos a serem obrigatoriamente seguidos. A vivência da docência, exercida pelo professor no decorrer de sua carreira não pode ser entendida a partir de único modelo de ensino a ser adotado. Há, constantemente a necessidade do docente se atualizar, auto avaliar e procurar melhorar cada vez mais sua forma de ensinar (ROLDÃO, 2007).

Pimenta (2008, p. 01) descreve o ensino como "[...] fenômeno complexo, enquanto prática social realizada por e com seres humanos, é modificado pela ação e relação desses sujeitos que, por sua vez, são modificados nesse processo". Argumenta, também, que a identidade do professor não é uma constante fixa, emerge em dado contexto e momento históricos, tomando contornos conforme necessidades postas pela sociedade e se constrói a partir dos significados sociais a ela atribuídos (PIMENTA, 2008).

No exercício da docência, além da necessidade de formação profissional, da formação continuada e dos conhecimentos específicos à área de atuação, são requeridas também algumas competências referentes às rotinas docentes relacionadas diretamente aos atores envolvidos nesse campo de atuação, tais como os pares de profissão, a o corpo diretivo das instituições, a coordenação e todo corpo docente. Além dos sujeitos profissionais, estão envolvidos também os próprios estudantes, que são a razão da existência do docente em sua função. (VEIGA, 2006; PIMENTA, 2008).

Para Silva, Almeida e Gatti (2016), os conhecimentos técnicos e pedagógicos para o desenvolvimento da docência não são adquiridos de forma espontânea, há um trabalho progressivo e organizado para o ensino e para melhor desenvolver o ato de ensinar. É preciso rever cada contexto e analisar as exigências relacionadas às disciplinas e turmas. Destacam também que experiências exitosas passadas não significam garantia de sucesso no presente. Sob a mesma ótica, Pimenta $(2008$, p. 3) enfatiza que a "atitude de flexibilidade, abertura, capacidade de lidar com o imprevisto e o novo se tornam essenciais ao desempenho e sucesso da atividade docente.".

Sendo a docência a "profissão do conhecimento" (GARCÍA, 2009, p. 08) e o 
conhecimento e o saber os elementos principais para a docência, além do compromisso com a transformação desses saberes em aprendizagem significativa para os alunos, García (2009) afirma que o professor pode influenciar de maneira significativa o processo de aprendizagem dos alunos. Para o autor, "O ensino é um trabalho exigente e não é qualquer pessoa que consegue ser um professor eficaz e manter essa eficácia ao longo do tempo." (GARCÍA, 2009, p. 08).

A construção do conhecimento profissional docente exige a aquisição de diversos saberes, dentre eles, os teóricos, os práticos, os científicos e os pedagógicos. Roldão $(2007$, p. 98) identifica duas principais linhas para essa construção, a primeira é realizada através da "desmontagem analítica dos componentes envolvidos no conhecimento global docente", uma análise na construção docente através da separação dos saberes que envolvem a docência e que possam contribuir para a construção da formação deste profissional; e a outra é centrada em um processo de reflexão através da própria ação profissional docente.

Diferenciada das demais profissionalizações, a profissão docente é distinguida por um saber específico: a "ação de ensinar" (ROLDÃO, 2007, p. 94), atemporal em sua essência, entretanto, mutável conforme o contexto sócio educacional da época.

Para Roldão (2007, p. 94), ensinar é a especialidade de fazer aprender alguma coisa a alguém. Para a autora, esta ação está dubiamente entendida entre "o professar um saber" e o "fazer outros apropriarem de um saber". A autora argumenta que ensinar como sinônimo de transmitir um saber deixou de ser socialmente útil, e aponta a existência de uma dificuldade, na ação do docente, em disseminar um saber e fazer com este chegue de forma eficaz aos alunos.

$O$ ato de ensinar está relacionado diretamente à forma como o professor desenvolve e aperfeiçoa sua metodologia no ensino, seja através de conversas com seus pares, auto avaliações, experimentos inovadores ou outras ações. Silva, Almeida e Gatti (2016) apresentam como indicadores para a ação docente que influenciam a formação e o desenvolvimento da profissão: (a) o conhecimento profissional do professor, que são as aquisições de diferentes saberes para ajudar a prática educacional; (b) a prática profissional dos professores, que envolve sua ação nas formas de criação da aprendizagem para os alunos; e (c) o engajamento profissional do professor, que se relaciona com a participação do docente em seu ambiente de trabalho.

Roldão $(2005$, p. 114) ressalta que "o saber próprio do docente é o elo mais fraco na construção social" deste profissional, e que o saber necessário à prática da função docente está socialmente atribuído ao ato de ensinar. E indaga:

Que é o saber profissional do professor? Que relação tem com a função de ensinar, definidora da atividade? Como é visto o ato de ensinar pelos próprios que o desempenham? Que tipo de saber requer? E como se constitui, ou não, esse saber no fundamento legitimador da ação docente? (ROLDÃO, 2005, p. 114).

Roldão argumenta que a docência, entendida e percebida em um contexto geral por quem está com um olhar afastado da realidade, é uma profissão consideravelmente fácil, pois para ser professor basta saber sobre a disciplina lecionada e ter certo controle sobre os alunos. Enfatiza, contudo, que o saber, especificidade da função do docente, está diretamente atrelado à interpretação social relacionada à ação de ensinar. Destaca ainda que os docentes representam um relevante papel "[...] porque são - ou devem ser - os que fazem os outros (que hoje são todos os cidadãos) aprender um saber que socialmente se considera que lhes é necessário." (ROLDÃO, 2005, p. 115).

Em outra perspectiva, García (2009) aborda o desenvolvimento profissional e o processo de se tornar professor, como evoluções desenvolvidas em longo prazo em um campo vasto e diversificado de conhecimentos que integra diferentes oportunidades e experiências. Entretanto, para essa afirmação, o autor apresenta um questionamento: como manter a docência como uma profissão atrativa para que os professores continuem sempre a aprender durante suas carreiras?

Embora seja possível encontrar algumas definições para a docência em uma perspectiva mais ampla, autores brasileiros do campo da docência superior afirmam que o entendimento da docência voltada ao ensino superior, ainda é um assunto a ser investigado e aprofundado. 
Conforme Isaia (2006, p. 63), "[...] a docência superior é um processo complexo que se constrói ao longo da trajetória docente e esta envolve, de forma intrinsecamente relacionada, a dimensão pessoal, a profissional e a institucional.". Para a autora, a composição dessas três dimensões está relacionada à construção do perfil do docente no ensino superior.

De acordo com Pimenta e Anastasiou (2002, p. 199), para o exercício da profissão docente voltada ao ensino superior, não existe um modelo ou padrão a ser seguido. "Não há modelos ou experiências modelares a serem aplicadas. A experiência acumulada serve apenas de referência, nunca de padrão de ações com segurança e sucesso.".

Em razão dessa falta de referência e padrões a serem seguidos, e até mesmo da ausência de uma formação específica para o docente que pretende atuar no ensino superior, o mesmo pode desenvolver sua carreira acadêmica a partir de um conjunto de fatores que envolverão sua trajetória pessoal, seu cotidiano, seus desafios e experiências profissionais enquanto docente, além dos contextos acadêmicos e curriculares vivenciados nas diferentes instituições de ensino (ISAIA, 2006).

Apesar de a docência necessitar de formação pedagógica para o seu exercício, a atuação docentes em sala de aula é geralmente pautada por experiências acumuladas pelo professor a cada semestre lecionado, sejam positivas ou não, e também alimentada por lembranças de quando era aluno e observava a atuação de seus professores em sala de aula.

A docência no ensino superior é
desenvolvida por semestres, ou aproximadamente a cada quatro ou cinco meses. Em função desse curto período de convivência entre docente e alunos, a forma de ensino é moldada a cada semestre letivo, sendo o processo de ensino-aprendizagem influenciado conforme o calendário acadêmico, podendo sofrer interferências com os excessos de feriados nacionais, municipais e até mesmo greves da categoria. Em razão desse curto espaço de tempo e desenvolvimento, e suas possíveis variáveis, não há garantia de que a forma como o docente trabalhou com determinado conteúdo acadêmico, se aplique da mesma forma a outra turma no semestre seguinte (PIMENTA, 2008).

Essa multiplicidade de variáveis e também de atribuições designadas ao docente, requer uma formação que o capacite acadêmica e pedagogicamente para enfrentar os desafios imprescindíveis do cotidiano relacionado ao ensino superior. Há, no entanto, um longo e intrincado caminho a ser percorrido, visto que, concretamente os docentes iniciam seus passos na docência superior de forma solitária, tomando suas próprias decisões, auto avaliando-se, seguindo normas institucionais e, vez ou outra, conversando com seus pares (VEIGA, 2006). Isaia (2006), por sua vez, ressalta a falta de preocupação por parte dos docentes e das instituições com a formação destinada ao preparo profissional para a docência, e argumenta que, mesmo cientes de sua função formativa, não consideram necessária uma preparação específica para exercê-la. Muitos deles sentem-se aptos ao desafio pedagógico tendo apenas como base a experiência profissional.

Sobre a falta de formação pedagógica específica para a docência dos professores que atuam em nível superior, Barbosa (2011) denuncia o notório consentimento por parte das IES para com este quadro, e acrescenta que é, de certa forma, consensual a ideia de que o docente de nível superior não necessita de uma formação no campo educacional, bastando apenas ter a expertise e o conhecimento específico da disciplina que leciona. É possível, então afirmar, conforme a literatura pertinente, que, na maioria das instituições de ensino superior, incluindo as Universidades, embora seus professores possuam experiência significativa e mesmo anos de estudos em suas áreas específicas, predomina a falta de formação e até o desconhecimento científico do que seja o processo de ensino/aprendizagem, pelo qual passam a ser responsáveis a partir do instante em que ingressam na sala de aula.

Pimenta (2008) ressalta que o mercado de trabalho dos professores está sendo ocupado por profissionais de diversas áreas oriundos do mercado de trabalho, com a intenção do aproveitamento de expertises e do conhecimento técnico. E argumenta que falta algo para este profissional recém-chegado à docência.

Entre o mercado e a sala de aula: Professores iniciantes no curso de Comunicação Social

A pesquisa foi realizada em duas IES privadas (denominadas, para efeito deste trabalho, IES A e IES B) do município do Rio de Janeiro, mais especificamente em dois cursos superiores de Comunicação Social, nas especialidades de Publicidade e Propaganda e Jornalismo. Tratando-se de investigação de 
natureza qualitativa, a entrevista semiestruturada foi o procedimento considerado mais adequado, nos limites da pesquisa, para a obtenção de informações sobre a prática docente dos professores das IES já referidas. Como respondentes, foram selecionados docentes que começaram profissionalmente no mercado e posteriormente passaram a atuar no ensino superior, e também, os coordenadores desses cursos. ${ }^{1}$ Foram realizadas, no total, 10 entrevistas. A fim de manter o anonimato dos sujeitos da pesquisa, nomes fictícios Ihes foram atribuídos.

$O$ roteiro para as entrevistas foi dividido conforme os objetivos da pesquisa. O primeiro bloco teve como propósito conhecer o perfil do professor. No segundo, o objetivo foi compreender a trajetória do professor até o inicio na docência. O terceiro bloco foi destinado a compreender os desafios encontrados no início da docência. O bloco final teve como propósito compreender como o professor enfrentou esses desafios.

As entrevistas foram transcritas integralmente e, após a realização de uma síntese das informações relacionadas ao perfil dos professores, apresentado na sequência, procedeu-se à análise de conteúdo das informações relativas aos desafios da prática docente, bem como às estratégias às quais recorreram enfrentá-los. Após a fase da préanálise (BARDIN, 2010), que incluiu a leitura flutuante, procedeu-se à análise do material transcrito, a qual, sempre considerando as questões de pesquisa e o referencial teórico foi organizada em duas categorias principais, a saber: "Trajetórias" e "Desafios". As informações relativas às trajetórias incluíram a busca por cursos de especialização e as formas de ingresso na docência superior; na descrição dos desafios surgiram também as variadas formas que os professores engendraram para enfrentá-los.

\section{Os professores: formação atuação e tempo na docência}

Quanto ao perfil dos professores, dos dez docentes entrevistados, quatro não se graduaram especificamente em Comunicação Social. Dois têm menos de dez anos de formação; os demais têm dez anos ou mais; somente um cursou o doutorado, dois são doutorandos, três têm título de mestre, um está com o mestrado em curso e três são especialistas. Quando perguntados sobre a atual atividade profissional, apenas quatro professores informaram dedicação exclusiva à docência. Os demais conciliam com atividades relacionadas ao mercado.

Quanto ao tempo de docência, apenas um dos entrevistados leciona há mais de 30 anos; dois exercem a docência há mais de 20 anos, quatro entre 10 e 20 anos, e os outros três há menos de dez anos. Desses últimos, um ainda não completou um ano lecionando.

No que se refere às disciplinas lecionadas pelos entrevistados, a predominância está relacionada às práticas de mercado, tanto para Publicidade e Propaganda quanto para Jornalismo. Salvo as disciplinas de Design Consumo e Cultura, Antropologia do Consumo e Fundamentos Históricos do Design, matérias com abordagens mais teóricas, lecionadas respectivamente pelos docentes Lúcio, Marcos e Rodrigo, as demais contribuem diretamente para a formação prática do aluno de Comunicação Social.

\footnotetext{
${ }^{1}$ Neste trabalho trataremos apenas das informações obtidas por meio das entrevistas com os professores.
} 
Quadro 1. Tempo de docência e disciplinas lecionadas

\begin{tabular}{|c|c|c|}
\hline Identificação & $\begin{array}{l}\text { Tempo de } \\
\text { docência }\end{array}$ & Disciplinas que leciona \\
\hline Ana & 10 anos & $\begin{array}{l}\text { - Comunicação e Marketing } \\
\text { - Planejamento Estratégico } \\
\text { - Comunicação Empresarial }\end{array}$ \\
\hline Anderson & 18 anos & $\begin{array}{l}\text { - Radio jornalismo } \\
\text { - Telejornalismo } \\
\text { - Assessoria em Comunicação }\end{array}$ \\
\hline Júnior & 21 anos & $\begin{array}{l}\text { - Editoração Eletrônica I } \\
\text { - Editoração Eletrônica II }\end{array}$ \\
\hline Leandro & 21 anos & $\begin{array}{l}\text { - Introdução a Fotografia } \\
\text { - Fotografia e Imagem }\end{array}$ \\
\hline Lúcio & 7 meses & $\begin{array}{l}\text { - Criação } \\
\text { - Design Consumo e Cultura } \\
\text { - Branding }\end{array}$ \\
\hline Luís & 11 anos & $\begin{array}{l}\text { - Radio jornalismo } \\
\text { - Jornalismo esportivo } \\
\text { - Introdução a Comunicação }\end{array}$ \\
\hline Marcos & 18 anos & $\begin{array}{l}\text { - Inovação e criatividade } \\
\text { - Cibercultura } \\
\text { - Antropologia do Consumo } \\
\text { - Marketing e Mídias Sociais Digitais }\end{array}$ \\
\hline Rodrigo & 8 anos & $\begin{array}{l}\text { - Fundamentos Históricos do Design } \\
\text { - Identidade Visual } \\
\text { - Diagramação }\end{array}$ \\
\hline Rogério & 34 anos & $\begin{array}{l}\text { - Marketing } \\
\text { - Gestão de Produto } \\
\text { - Branding }\end{array}$ \\
\hline Vitória & 6 anos & $\begin{array}{l}\text { - Introdução a Fotografia } \\
\text { - Foto publicidade } \\
\text { - Fotojornalismo }\end{array}$ \\
\hline
\end{tabular}

Fonte: Elaborado pelos autores a partir dos dados colhidos nas entrevistas.

Cabe ressaltar que, embora alguns tenham muitos anos de experiência em sala de aula, nenhum dos entrevistados obteve qualquer formação pedagógica ao longo do desenvolvimento da docência. Esta situação reforça o afirmado por Benedito (1995 apud PIMENTA, 2008, p. 1), para quem o professor do ensino superior "aprende a sê-lo mediante um processo de socialização em parte intuitiva, autodidata (...) seguindo a rotina dos 'outros'. [...].

\section{Trajetórias: do mercado para a sala de aula}

O exercício da profissão docente requer um modelo de profissional versátil, no qual o professor esteja disposto a desempenhar algumas funções que vão além da sala de aula. Conforme afirma Veiga (2006), a jornada docente ultrapassa a hora-aula ministrada pois, por vezes, outras tarefas que vão além da jornada profissional do docente são requeridas. Contudo, é possível constatar que muitos dos professores advindos do mercado de trabalho, recrutados em razão de suas expertises profissionais ou atraídos pelo exercício da docência, não possuem o conhecimento necessário sobre outras tarefas profissionais exigidas pela carreira. Tanto aquelas relacionadas a questões acadêmicas, como planejamento e avaliação, quanto as de viés mais burocrático, como preenchimento de diário, por exemplo.

Na sequência, buscou-se compreender o caminho percorrido pelo profissional até a iniciação na docência. $O$ resultado mostrou que todos começaram suas carreiras profissionais no mercado de trabalho. Contudo os professores Lúcio e Rogério já exerciam concomitantemente a docência. Ensinavam em cursos pré-vestibulares mas, à época, não objetivavam ainda a docência 
no ensino superior. O professor Rogério teve um início na docência parecido com de outros entrevistados que iniciaram suas atividades docentes a partir de convites recebidos. Foi convidado a dar aula em um curso pré-vestibular, no mesmo colégio em que se formou no ensino médio, logo após a conclusão do mesmo, conforme descreve:

Quando eu acabei o curso fui lá um dia depois da aula e um professor falou assim: "Poxa você é garotão, tem que ter um dinheiro teu, não quer dar aula com a gente?". Então, eu com 17 para 18 anos, comecei a dar aula de álgebra (Professor Rogério).

Quanto à docência superior, quatro dos entrevistados iniciaram-se na docência superior por meio de convites feitos por outros professores, em razão de serem portadores de determinadas habilidades profissionais e não por possuírem qualquer experiência ou vivência pedagógica, ou seja, o avesso do que destaca Veiga $(2006$, p. 87) como formação para o exercício da docência superior. A autora destaca a necessidade de "[...] conhecimentos específicos para exercê-los adequadamente ou, no mínimo, a aquisição dos conhecimentos e das habilidades vinculadas à atividade docente para melhorar sua qualidade.".

O professor Rodrigo começou a dar aulas após um convite de um professor da IES B, que havia sido seu coordenador na agência experimental $^{2}$ em determinada instituição superior:

Nunca na minha vida eu pensei em ser professor, nunca pensei em nada relativo à docência. Até mesmo pra aceitar o convite de ser professor eu fiquei meio reticente de aceitar. Eu pensei: "Será que eu tenho jeito?". E a pessoa que me convidou me conhecia, eu já tinha feito alguns trabalhos com ele, e ele falou: "Você fala bem, você tem paciência.".

\footnotetext{
2 Agência de publicidade desenvolvida dentro de uma IES, coordenada por um professor do curso e composta e desenvolvida por alunos, com o objetivo acadêmico de retratar uma verdadeira agência.
}

Ele foi me convencendo a ser professor. Aí eu falei: “Então, tá bom, vou pegar uma ou duas disciplinas e a gente vê no que dá. E aí se der certo eu vou ficando." (Professor Rodrigo).

Os professores Marcos e Rogério também começaram a atuar no ensino superior sem qualquer formação pedagógica anterior e sem serem submetidos a qualquer tipo de processo seletivo. Foram convidados por amigos professores e decidiram aceitar o desafio. $\mathrm{O}$ que pesou para serem convidados foi a experiência de mercado que já possuíam.

A motivação do professor Marcos para aceitar o convite foi o foi o fato de sentir-se desafiado a dar aulas como gostaria que tivessem sido as suas durante a graduação.

Foi uma coisa de surpresa. Eu tinha um grande amigo que tinha começado a dar aula. Ele virou pra mim e falou: "Poxa comecei a dar aula, tô adorando, você podia dar aula também.". Ele virou pra mim e falou: "Vamos fazer uma entrevista.". Aí eu pensei comigo: "Na minha formação eu tive muito professor ruim, muito.". Aí falei: "Poxa, eu queria ter tido uma aula mais legal.". Eu vou lá, vou dar aula e vou dar aula que eu queria ter tido." Eles precisavam de um professor pra dar aula de oficina de criação, trabalhava com isso há quase 10 anos. Levei meu portfólio e mostrei ao diretor do curso. Ele olhou pra mim e disse: "Eu achei você falante, gostei do seu portfólio. Eu acho que você vai dar certo.". Me chamou e comecei a dar aula (Professor Marcos).

Também sem ter sido submetido a qualquer processo seletivo, o professor Rogério recebeu um convite para dar aula de Marketing para uma turma de Comunicação Social, pois tinha se formado recentemente em Administração. Rogério ainda não cursara a graduação em Publicidade e Propaganda. O 
convite surgiu devido a ausência de um dos professores para a disciplina de Marketing o conforme relato seguinte:

$$
\begin{aligned}
& \text { A graduação em } \\
& \text { Comunicação Social foi } \\
& \text { aparecer depois que eu } \\
& \text { acabei a de Administração. } \\
& \text { Quando comecei a dar } \\
& \text { aula, eu já tinha acabado } \\
& \text { Administração, por isso eu } \\
& \text { vim dar aula de Marketing. } \\
& \text { A pessoa me ligou assim e } \\
& \text { disse: "Não posso deixar a } \\
& \text { turma sem aula, vem que } \\
& \text { você vai gostar.". Eu estava } \\
& \text { meio na dúvida com aquele } \\
& \text { compromisso semanal } \\
& \text { (Professor Rogério). }
\end{aligned}
$$

O professor Júnior também recebeu um convite para a docência devido a sua experiência profissional: "Eu já trabalhava aqui (na IES A) como diagramador e coordenava o laboratório de artes gráficas e editoração eletrônica da empresa, apresentei um projeto e eles gostaram. E aí fui chamado para ser professor" (Professor Júnior).

O professor Anderson teve o interesse pela docência despertado a partir do incentivo de alguns de seus estagiários de uma redação de rádio: escrever dessa maneira.". E eu que tinha mais paciência. $\mathrm{E}$ muitos falavam isso: "Você dá aula? Você é professor?". E aquilo um dia despertou. $\mathrm{E}$ eu falei: “Por que, não?" (Professor Anderson).

Com relação ao caminho percorrido até o ingresso na docência, os resultados mostram que quatro dos entrevistados cursaram pós-graduação lato sensu visando à docência; destes, dois fizeram especificamente a especialização em Docência no Ensino Superior; um já era especialista e não fez qualquer outro curso de formação; três, somente algum tempo depois do início na docência especializaram-se em Docência no Ensino Superior. Apenas um dos entrevistados fez o Mestrado como forma de preparo ao ingresso; e um último somente depois do Mestrado optou pela carreira docente.

De acordo com os depoimentos, o caminho percorrido até o ingresso na docência pelos entrevistados não obedeceu a uma formação específica ou um sistema de políticas voltado ao ingresso na docência superior. 0 cenário exposto corrobora a falta de uma formação especifica para o docente, ao mesmo tempo em que evidencia a falta de políticas públicas claras destinadas à formação pedagógica para este nível de ensino (VEIGA, 2006), além da anuência das IES com a situação.

\section{Os desafios da docência e as estratégias para enfrentá-los}

Devido à falta de uma formação própria destinada à docência no ensino superior e de modelos consolidados a serem seguidos, por vezes os docentes iniciantes nesse nível de ensino são obrigados a improvisar e seguir modelos de outros professores até se sentirem seguros para desenvolver suas próprias metodologias de ensino. Conforme argumenta Isaia (2006), o professor pode desenvolver sua carreira mediante um conjunto de fatores que envolvem sua própria vivência pessoal e profissional, além dos cenários acadêmicos vivenciados no ensino superior.

Tendo em vista que os cursos de licenciatura são destinados à formação do docente voltada à educação básica, ao mesmo tempo em que os cursos de bacharelado formam seus graduados para o mercado sem qualquer orientação pedagógica, faz-se necessário o entendimento dos desafios e dificuldades 
enfrentadas pelos professores ao desempenhar a docência.

Ao indagarmos aos entrevistados sobre como foram os primeiros dias na sala de aula, apenas dois informaram terem se sentido confortáveis com o novo desafio; os demais relataram nervosismo e falta de preparo para lidar com algumas situações, das quais destacamos: (a) Lidar com alunos de várias classes e idades; (b) diversidade cultural dos alunos; (c) turmas grandes. (d) gestão de classe e de tempo de aula; (e) lidar com perguntas mais delicadas; (f) buscar o respeito por ter idade próxima à dos alunos; (g) comportamento e postura a assumir em sala; (h) lidar na teoria com o que lida na prática; (i) necessidade de improvisar; (j) insegurança.

De forma a ilustrar os desafios mencionados, destacamos alguns depoimentos dos entrevistados, relacionadas à sua iniciação na docência:

Foram desafiantes. Até porque no primeiro dia de aula, você nunca viu a turma. Até hoje sinto um certo receio ao pisar numa sala, claro que não tanto quanto. E principalmente quando eu comecei, as turmas eram gigantescas era tipo um auditório. É difícil uma turma de 80, 100 alunos (Professora Ana).

Nervoso pra caramba, assim, de imaginar como que eles iam me receber. Em casa falei na frente do espelho, aquela coisa toda, mas fiquei nervoso $e$ olhava para os alunos que estavam sentados ali e que todos imaginavam "Esse cara deve estar nervoso pra caramba.", e criaram uma expectativa, porque quando eu entrei eles falaram: "Está chegando um professor novo.". Tudo que é novo cria uma expectativa (Professor Anderson).

Vou confessar para você que deu um frio na barriga. Porque você lidar com alunos de várias classes, várias idades inclusive, de vários pensamentos e de várias metodologias, então, você para poder controlar essa turma e passar informação realmente é difícil, não foi fácil nos primeiros dias (Professor Júnior).

Nos primeiros dias rolava uma certa apreensão. Como um artista subindo no palco na estreia, sempre causava um certo frio na barriga (Professor Leandro).

$\mathrm{Na}$ sequência, são destacadas as estratégias utilizadas pelos entrevistados para fazer frente à falta de preparo para o exercício da função: (a) Voz firme; (b) falar sobre a experiência profissional; (c) treino em casa; (d) estudo de matérias do ensino fundamental e médio para poder ministrar a disciplina; (e) trazer temas atrativos; (f) aulas no laboratório; (g) improviso; (h) assumir a postura do "quem sabe sou eu"; (i) incentivar a participação dos alunos; (j) diversificar as técnicas; ( $\mathrm{k}$ ) trazer a aula para o momento atual (histórico, político, cultural); (I) trabalhar com muitas imagens, para prender a atenção. Embora tenham sido mencionadas conversas pontuais e experiências trocadas com seus pares ou participação em eventos acadêmicas desenvolvidos a cada novo semestre, nota-se que, na ausência de formação pedagógica anterior, os respondentes criaram suas próprias estratégias, por ensaio e erro, estudando, procurando ver o que funcionava e até mesmo improvisando, responsabilizando-se, assim, integral e solitariamente por sua própria formação.

Ao questionar os entrevistados se sentiram dificuldade no início da docência devido à falta dessa formação, seis alegaram que poderiam ter tido um início na docência mais qualificado se tivessem tido uma base pedagógica, contudo, dois professores alegaram que não sentiram essa dificuldade, e que não sabem como uma formação pedagógica adequada poderia melhorar sua prática de ensino. Na ausência dessa formação, foram improvisando e criando suas próprias metodologias.

Três dos professores argumentaram que não sentiram falta da formação pedagógica devido ao conhecimento profissional que já detinham e que utilizaram na sala de aula, 
sentindo-se, por essa razão, confiantes e preparados. Um professor não soube avaliar. Disse que lançou mão do conhecimento de mercado e não soube opinar se realmente a ausência da formação pedagógica fez diferença. 0 que chama atenção, nesse caso, é que apesar do conhecimento e experiência adquirida em áreas específicas, prevalece, como apontam, Pimenta e Anastasiou, (2002, p. 37), "[...] o despreparo e até um desconhecimento científico do que seja o processo de ensino/aprendizagem, pelo qual passam a ser responsáveis a partir do instante em que ingressam na sala de aula.".

Diante da negativa de alguns, conforme relatado anteriormente, de que a formação pedagógica seria necessária para o exercício da docência, buscou-se saber de que estratégias lançaram mão para transformar 0 saber profissional em saber pedagógico, principalmente no início da carreira docente. Quando questionados se a experiência profissional ajudou na dinâmica de aula, de forma unânime, os professores responderam afirmativamente. A resposta mais comum entre os professores foi a da apresentação aos alunos das experiências do mercado, conforme ilustram os trechos abaixo:

Para ensinar existem várias didáticas, várias formas de ensinar. E eu levei uma que eu dizia o seguinte: "Eu vou levar o mercado de trabalho para sala de aula.", ou seja, como é lá. Eu vou transformar a sala de aula numa redação. E isso vem dando certo, acho que os alunos aprendem. (Professor Anderson).

Total, total. A ponto de no início eu desprezar e rejeitar e ter até certo preconceito com o conhecimento acadêmico. Eu achava muito "blá blá blá" e pouco resultado (Professor Rogério).

Segundo relataram, a experiência profissional ajudou a forma de fazer com que os alunos entendessem a disciplina por meio de exemplos práticos e histórias vivenciadas. Entretanto, destacamos dois extratos de entrevistas que fazem uma ressalva sobre professores recrutados do mercado. 0 professor
Leandro diz que, apesar da experiência de mercado ter ajudado, "Você pode ter muita experiência e não conseguir transmitir absolutamente nada." $E$, nessa mesma direção, o professor Marcos destaca que:

O professor que é muito preso ao pensamento de mercado, ele quer fazer as coisas muito "pá-pum", ele quer transmitir que as coisas são muito dentro de insights, dentro do talento individual, da intuição. Eu acho que ele tá equivocado nisso, eu acho que tudo vem de um background $\mathrm{e}$ eu tenho que dar para o aluno justamente esse background. Que o cara do mercado talvez até intua que precisa, mas ele não sabe transmitir porque falta pra ele mesmo.

As respostas dos professores Leandro e Marcos corroboram a afirmação de García (2009), quando o autor diz que o docente pode interferir no processo de ensino, seja para um melhor aprendizado ou não. Essa dificuldade também é abordada por Roldão (2007), quando a autora se refere à propagação de um saber específico por meio do professor e a forma com que esse saber pode ser aprendido pelos alunos.

Outro aspecto relacionado ao trabalho docente desenvolvido pelos participantes da pesquisa lembra a advertência de Pimenta (2008), para quem a atuação da docência superior pode ser desenvolvida com suporte em lembranças de quando o docente ainda era aluno. Esta situação é evidenciada pela fala do professor Rodrigo (no quadro 2) que informa ter-se baseado em sua memória de quando era estudante, além de suas experiências profissionais.

O quadro 2 descreve como os entrevistados direcionaram o que vivenciaram na prática em sala de aula. Os entrevistados procuram relatar suas experiências profissionais e como as levaram para a sala de aula, simulando situações reais, trabalhando com o imprevisível e até mesmo colocando os estudantes em situações de cobrança e estresse, como de fato ocorre no mundo do trabalho. 
Quadro 2. Transformação do saber prático em teórico

\begin{tabular}{|c|c|}
\hline Nome & Estratégias utilizadas \\
\hline Ana & $\begin{array}{l}\text { - Utiliza relatos sobre o mercado. } \\
\text { - Aborda experiências que já passou. } \\
\text { - Compara presente e passado. }\end{array}$ \\
\hline Anderson & $\begin{array}{l}\text { - Aborda experiências de mercado. } \\
\text { - Trabalha com fatos recentes e como eles funcionam na prática. } \\
\text { - Coloca os alunos em situação de "stress", como no mercado. } \\
\text { - Traz referências bibliográficas para o momento atual do mercado. }\end{array}$ \\
\hline Júnior & $\begin{array}{l}\text { - Simula situações reais. } \\
\text { - Coloca os alunos para produzirem exatamente como no mercado, cada um } \\
\text { com uma atribuição. }\end{array}$ \\
\hline Leandro & $\begin{array}{l}\text { - Leva imagens de fotógrafos profissionais. } \\
\text { - Leva suas próprias imagens e mostra com foram feitas. } \\
\text { - Fala sobre "gostos" na hora de fotografar e como faz para que saiam do seu } \\
\text { jeito. }\end{array}$ \\
\hline Lúcio & $\begin{array}{l}\text { - Apresenta trabalhos que tenha desenvolvido no mercado. } \\
\text { - Trabalha com cases e apresenta os diagnósticos e soluções segundo sua } \\
\text { experiência. } \\
\text { - Relaciona a teoria que está aplicando com o momento do mercado. } \\
\text { - Tenta apresentar a dinâmica do mercado. }\end{array}$ \\
\hline Luís & $\begin{array}{l}\text { - Trabalha o imprevisível. } \\
\text { - Aborda experiências de mercado. } \\
\text { - Faz com que eles se sintam como se estivessem no mercado. } \\
\text { - Aproxima ao máximo a realidade do mercado. }\end{array}$ \\
\hline Marcos & $\begin{array}{l}\text { - Faz o aluno se colocar numa situação como na realidade. } \\
\text { - É exigente com o aluno como o mercado é. } \\
\text { - É desafiador com o aluno, forçando a trabalhar cada vez melhor e errar } \\
\text { menos. } \\
\text { - Traz suas experiências de mercado. }\end{array}$ \\
\hline Rodrigo & $\begin{array}{l}\text { - Tenta se basear em suas lembranças, suas experiências. } \\
\text { - Transforma as experiências de mercado em "problema" para o aluno. } \\
\text { - Coloca-se na posição de questionador para verificar o aprendizado. }\end{array}$ \\
\hline Rogério & $\begin{array}{l}\text { - Traz suas experiências de mercado. } \\
\text { - Leva para sala de aula coisas que estão acontecendo no mercado, todas as } \\
\text { novidades e tendências. } \\
\text { - Leva para sala de aula trabalhos atuais dos próprios alunos que estão no } \\
\text { mercado para que eles apresentem para turma. }\end{array}$ \\
\hline Vitória & $\begin{array}{l}\text { - Troca experiências. } \\
\text { - Apresenta problemas reais. } \\
\text { - Traz exemplos do mercado e coloca os alunos nessa situação. } \\
\text { - Adapta as aulas para o que o mercado pede. } \\
\text { - Mostra as situações vividas e desenvolve soluções. }\end{array}$ \\
\hline
\end{tabular}

Fonte: Elaborado pelos autores a partir dos dados colhidos nas entrevistas.

No tocante ao preparo de materiais pedagógicos para as aulas, em razão da ausência de uma formação destinada propriamente à educação superior, alguns docentes, principalmente os recém contratados, se veem obrigados a improvisar a metodologia de ensino, tomando como base exemplos passados ou testando, a cada ciclo, formas diferenciadas de lecionar. Esse cenário é destacado pelo professor Rogério que, sobre o início da docência afirmou: "Eu não tinha nenhuma informação, eu fui fazendo do meu jeito. Todo mundo, acho, começa assim.". 
Quanto aos recursos utilizados, os que mais se destacaram foram: (a) Uso de projetor com slides no Power Point; (b) indicação de referências bibliográficas; (c) utilização de vídeos em sala de aula; (d) material de mercado como exemplo (impressos em geral); e (e) estudos de caso.

De acordo com a resposta do professor Luís (2018), para os alunos se acostumarem com os acontecimentos relacionados ao mundo do trabalho, lança mão em suas aulas do elemento surpresa. Afirma que suas aulas nunca são iguais, os alunos nunca vão saber o que vai acontecer:

Nunca é a mesma aula, a ideia qual é? É fazer como se eles estivessem numa redação: "E aí, o que vai ter hoje? Não sei, eu estou chegando pra trabalhar, mas eu não faço a menor ideia.". Eu tento fazer sempre isso pra justamente tirar essa previsibilidade (Professor Luís).

Para o professor Rogério (2018), uma das maiores mudanças em sua forma de lecionar foi estar disposto a utilizar técnicas e diversos instrumentos tecnológicos no uso da aula. Relatou ainda o uso de quizzes, com auxílio de seu próprio celular e também com os dos alunos.

A partir dessa análise foi possível constatar que os professores que têm somente a formação em nível de bacharelado iniciam a docência no ensino superior criando suas próprias metodologias, improvisando, quando necessário, contando ainda com a ajuda informal de seus pares e com base na experiência que a prática Ihes permite acumular.

\section{CONSIDERAÇÕES FINAIS}

Uma das principais indagações que surgiram a partir da pesquisa realizada pode ser assim sintetizada: como prover uma educação superior qualificada sem contar com iniciativas públicas e institucionais voltadas para a formação dos docentes que atuam nesse nível educacional?

Como já ressaltado por Barbosa (2011), no cenário da educação superior brasileira, a possibilidade de pleitear uma vaga na docência superior resume-se à obtenção de títulos acadêmicos ou à aquisição de habilidades profissionais em determinada área no mercado, além do conhecimento da disciplina a ser lecionada. Pimenta (2008) salienta que a carreira docente no ensino superior apresenta crescente demanda por profissionais do mercado, sendo os mesmos aproveitados por seus conhecimentos e experiências profissionais. Entretanto, além de aspectos mais estreitamente relacionados ao ofício de ensinar, alguns questionamentos se fazem necessários diante da ausência de uma previsão legal menos vaga no que se refere à formação do docente do ensino superior, independentemente do inegável valor, para os discentes, dos contatos com os conhecimentos derivados da expertise profissional de seus professores.

A ênfase na ideia de mercado, a qual atravessa a maioria dos depoimentos, deixa em plano secundário não apenas o papel da educação na formação geral dos indivíduos, praticamente reduzindo-a à dimensão da qualificação profissional, mas também a ideia de que, como lembram Gauthier et al (2013) o ensino se apoia sobre um repertório de conhecimentos próprios à sua prática.

O estudo do tema em questão também deixou claro, conforme os autores pesquisados, que tanto a identidade pessoal quanto a profissional são modificadas conforme as experiências adquiridas pelos os indivíduos no decorrer de suas vidas e carreiras profissionais. Assim também ocorre com a docência, moldada pela vivência cotidiana e ambiente acadêmico.

Conforme os resultados da pesquisa de campo, é possível notar que, apesar do tempo exercido na docência, os professores entrevistados aprenderam e ainda aprendem seu ofício no cotidiano das salas de aula, de forma autodidata e muitas vezes improvisada. No que tange à formação acadêmica visando à docência superior, notou-se que somente um dos entrevistados, recente no exercício da docência superior, cursou o mestrado objetivando exercer a profissão de professor, enquanto alguns procuraram cursos de especialização em docência superior, sem que houvesse menção em qualquer dos casos a qualquer iniciativa institucional para apoiar os iniciantes ou visando ao desenvolvimento profissional, já na carreira.

Sobre os desafios encontrados ao desempenhar a docência, foi percebido que o professor aprende também por ensaio e erro e que, em muitos casos, a experiência profissional, que é exatamente de onde dizem obter a segurança para lecionar, não basta, levando-os, então a recorrer à sua remota experiência 
discente, ao contato informal com os colegas ou mesmo ao improviso. Os professores entrevistados fizeram questão de sinalizar essa expertise em sala de aula para manter a atenção dos alunos, com o objetivo de mostrar que têm o conhecimento necessário para determinada disciplina. Contudo, isto não é suficiente, visto que se faz necessário, também, o envolvimento com as práticas pedagógicas e rotinas burocráticas acadêmicas, atividades nas quais os pares exercem papel fundamental. Cabe destacar, porém, o empenho dos professores em conquistar a participação e o interesse dos estudantes e de trazer a prática da profissão para a docência, fazendo com que os alunos conseguissem vislumbrar o futuro ofício na sala de aula.

Todos os entrevistados concordaram que a experiência de mercado ajudou e ainda ajuda na dinâmica da sala aula para as disciplinas práticas voltadas ao curso de Comunicação Social e também para outros cursos de bacharelado. Conforme relatos, as disciplinas voltadas à prática de mercado são mais valorizadas pelos alunos quando 0 docente tem essa vivência. A experiência de mercado não significa necessariamente êxito na docência, porém, em cursos de perfil profissional mais acentuado é inegável a necessidade de professores experientes para a docência das disciplinas práticas. Em suma, a experiência profissional pode ajudar na dinâmica de aula e pode ser bem vista pelos alunos, porém, para minimizar o aprendizado autodidata realizado pelo docente em seu dia a dia, há ainda que serem pensadas e planejadas políticas que estabeleçam diretrizes para a formação pedagógica inicial e continuada para o docente do ensino superior. Além do atendimento às necessidades formativas dos docentes que atuam no ensino superior, faz-se urgente também o aumento de pesquisas empíricas tornando o cotidiano na docência superior, especialmente do majoritário setor privado, mais conhecido.

\section{REFERÊNCIAS}

BARBOSA, J. R. A. Didática do Ensino Superior. Curitiba: IESDE Brasil S.A., 2011.

BRASIL. Censo da educação superior: 2015 resumo técnico. Brasília, 2018. Disponível em: <goo.gl/ckL92o>. Acesso em: 01 maio 2018.

BRASIL. Lei no 9.394, de 20 de dezembro de 1996. Estabelece as diretrizes e bases da educação
Nacional. Brasília, 1996. Disponível em: <goo.gl/SgGyLz>. Acesso em: 24 nov. 2016.

BARDIN, Laurence. Análise de conteúdo. 4. ed. Lisboa: Edições 70, 2010.

CRUZ, G.B. da. Didática e docência no ensino superior. Revista Brasileira de Estudos Pedagógicos, v. 98, n. 250. p. 672-689. 2017. DOI:10.24109/2176-6681.rbep.98i250.2931.

Disponível em: http://rbep.inep.gov.br/index.php/rbep/article/vi ew/2931. Acesso em: 15 jan.2018.

GARCÍA, C. M. Desenvolvimento profissional docente: passado e futuro. Revista de ciências da educação, n.8, p.7-22, 2009. Disponível em: $<$ https://goo.gl/v1H1BM>. Acesso em: 20 mai. 2017.

GATTI, Bernardete A. Questões sobre a docência universitária no Brasil. Entrevista concedida a Isabel Maria Sabino de Farias. Em Aberto, Brasília, v. 29 , n. 97 , p. 141-144, set/dez. 2016. Disponível em: <https://goo.gl/I2n7e6>. Acesso em: 28 out. 2017.

GAUTHIER et al. Por uma teoria da Pedagogia: pesquisas contemporâneas sobre 0 saber docente. 3. ed. ljuí: Unijuí, 2013.

ISAIA, S. M. de A. Desafios à docência superior: pressupostos a considerar. Docência na educação superior. Brasília: INEP, p. 63-84, 2006. Disponível em: <goo.gl/G2liCX>. Acessado em: 24 nov. 2016.

MASETTO, M.T. Professor Universitário: Um Profissional da Educação na Atividade Docente. Docência na Universidade. 1a. ed. Campinas: Papirus, 2012, v. 1, p. 07-122. Disponível em: <goo.gl/tsdvfz>. Acesso em: 28 abr. 2017.

NÓVOA, A. Firmar a posição como professor, afirmar a profissão docente. Cadernos de Pesquisa, v.47, n.166, p.1106-1133, 2017. DOI:10.1590/198053144843. Disponível em: http://www.scielo.br/scielo.php?script=sci_arttex $\mathrm{t} \& \mathrm{pid}=\mathrm{S} 0100$ 15742017000401106\&lng=pt\&tlng=pt. Acesso em:

PIMENTA, S. G. Docência na Universidade: ensino e pesquisa. São Paulo: Faculdade de Educação da 
USP, 2008. Disponível em: <goo.gl/8ZcCe5>. Acesso em: 25 nov. 2016.

PIMENTA, S.G; ANASTASIOU, L. das G. C. Docência no ensino superior. São Paulo: Cortez Editora, 2002.

ROLDÃO, M. C. Profissionalidade docente em análise - especificidades dos ensinos superior e não superior. Nuances: estudos sobre educação, v. 12, n. 13, 2005. Disponível em $<$ https://goo.gl/6p68yn>.

Acesso em: 20 mai. 2017.

ROLDÃO, M. C. Função docente: natureza e construção do conhecimento profissional. Revista Brasileira de Educação, Rio de Janeiro, v. 12, n. 34, p. 94-103, abr. 2007. Disponível em <goo.gl/T28jOw>. Acesso em: 24 nov. 2016.

SILVA, Vandré Gomes da; ALMEIDA, Patrícia Cristina Albieri de; GATTI, Bernardete Angelina. Referentes e critérios para a ação docente. Cadernos de Pesquisa, v. 46, n. 160, p. 286-311, 2016. Disponível em: <http:// goo.gl/ArUzKf $\geq$. Acesso em: 20 nov. 2016.

THERRIEN, J.; DIAS, A. M. I; LEITINHO, M. C. Docência universitária. Em Aberto, Brasília, v. 29, n. 97, p. 21-32, set/dez. 2016. Disponível em: <https://goo.gl/kUD33f>. Acesso em: 28 out. 2017.

VEIGA, I. P. A. Desafios à docência superior: pressupostos a considerar. Docência na educação superior. Brasília: INEP, p. 85-96, 2006. Disponível em: <goo.gl/G2liCx>. Acesso em: 24 nov. 2016.

Recebido para avaliação: 10/09/2018

Revisado em: 01/12/2018

Aceite Final: 01/12/2018 